ARTÍCULOS 



\title{
CRONOLOGÍA CERÁMICA EN CANCUÉN: HISTORIA DE UNA CIUDAD DEL CLÁSICO TARDÍO
}

\author{
MÉLANIE FoRnÉ \\ Silvia AlVARAdo \\ PAOLA TORRES \\ Proyecto Arqueológico Cancuén, Guatemala \\ Centro de Estudios Mexicanos y Centroamericanos
}

\begin{abstract}
Resumen: El sitio arqueológico Cancuén se destaca en el área maya del Clásico Tardío por su localización en el río de la Pasión, entre las Tierras Altas y las Tierras Bajas de Guatemala; desde allí la ciudad controló parte del flujo de bienes entre ambas áreas. Esto pudo comprobarse a través de la excavación de un taller de manufactura de artefactos de jade, cuya existencia fue un hecho único en las ciudades de Tierras Bajas. El estudio de la cerámica de este sitio presenta un doble reto: primero, ubicar Cancuén culturalmente, revelando una mezcla de influencias cerámicas procedentes de varias regiones vecinas. Una presentación sintética de la tipología permite vislumbrar la complejidad de las redes de intercambio y producción local de las vasijas. El segundo reto es el de establecer una cronología fina para los apenas 150 años de duración de la ocupación del sitio. La confrontación de la tipología cerámica con los datos epigráficos y los eventos políticos locales, permite establecer una secuencia cronológica completa, una de las primeras para esta zona fronteriza entre Tierras Bajas y Tierras Altas.
\end{abstract}

Palabras clave: Cancuén, cerámica, cronología, intercambio, frontera.

AвstRAct: Cancuén archaeological site is relevant within the Late Classic Maya context because of its geographical position on Pasión River, between Lowlands and Highlands of Guatemala, from where it controlled one of the greatest trade route between both areas. This has been evidenced by the excavation of a workshop where jade artifacts where produced, which is a unique discovery in Maya Lowlands. The analysis of ceramics in Cancuén represents a double challenge: first, it may define Cancuén's culturally, highlighting a mix of ceramic influences coming from different neighboring regions. A rapid presentation of the typology shows a quite complex panorama for exchange and local production of vessels. The second challenge is about establishing a fine chronology for the only 150 years of occupation. By confronting ceramic data with epigraphy and local political events, it has been possible to establish a detailed and complete chronology, one of the first in this frontier zone, between Lowlands and Highlands.

KEY words: Cancuén, ceramics, chronology, exchange, frontier.

ReCEPCIÓN: 17 de noviembre del 2009.

ACEPTACIÓN: 3 de marzo del 2011. 



\title{
CRONOLOGÍA CERÁMICA EN CANCUÉN: HISTORIA DE UNA CIUDAD DEL CLÁSICO TARDÍO*
}

\author{
MÉLANIE FoRnÉ \\ Silvia Alvarado \\ PaOla Torres \\ Proyecto Arqueológico Cancuén, Guatemala \\ Centro de Estudios Mexicanos y Centroamericanos
}

\section{Introducción}

Este artículo es una presentación general de la colección cerámica de Cancuén y de la secuencia cronológica establecida con base en el análisis cerámico. Éste empezó en el 2000, dirigido por Cassandra Bill (Bill, 2001; Bill y Callaghan, 2002; Bill, Callaghan y Castellanos, 2003; Callaghan y Bill, 2004), y luego, a partir de 2007, por Mélanie Forné, con un equipo de trabajo conformado por Silvia Alvarado y Paola Torres (Forné et al., 2008; 2009a; 2009b; 2010). El análisis de los arqueólogos Cassandra Bill, Michael Callaghan y Jeannette Castellanos (Bill, 2001; Bill y Callaghan, 2002; Bill, Callaghan y Castellanos, 2003) fue interrumpido en el 2004; y los trabajos de laboratorio, desde el 2007, se enfocaron en refinar las definiciones tipológicas y proseguir con el análisis cerámico.

Uno de los mayores retos para el estudio de la colección de Cancuén reside en la situación geográfica y cultural del sitio, en una zona intermedia entre las Tierras Bajas y Tierras Altas Mayas, así como en su papel clave en las dinámicas de intercambio de bienes de diferentes regiones, por lo cual la cerámica refleja una mezcla de materiales provenientes de varios lugares. Esta situación dificulta la identificación tipológica, la cual requiere de un examen comparativo de los estilos del Petén y los del Altiplano, un área de investigación generalmente poco conocida por los especialistas de las Tierras Bajas.

Sin embargo, la identificación tipológica presenta, hoy en día, algunos avances que queremos valorar aquí. Dichos avances permitieron llegar a la definición de una secuencia cronológica compuesta por tres complejos cerámicos que se presentarán a continuación (Forné et al., 2009a). Aunque el análisis aun no esté finalizado, estos resultados conforman avances significativos que pueden servir

\footnotetext{
"Este estudio no hubiera sido posible sin el completo apoyo del Proyecto Arqueológico Cancuén a través de su director, doctor A. A. Demarest, así como sin el arduo trabajo de equipo para la clasificación, registro y descripción cerámica por parte de las estudiantes avanzadas: Raquel Macario, Claudia Arriaza, Diana Belches, Antonieta Cajas; y de las practicantes Blanca Mijangos, Divina Perla, Suzana Sanchez, Gabriela Molina y Sandra Ventura.
} 
como base de comparación en la cual ya pueden apoyarse los investigadores que trabajan el área maya del Clásico Tardío.

\section{Cancuén: contexto geográfico e histórico}

El Proyecto Arqueológico Cancuén inició en 1999 bajo la dirección de Arthur A. Demarest (Universidad de Vanderbilt, Tennessee, Estados Unidos), codirigido por Tomás Barrientos (Universidad Del Valle, Guatemala) y, desde el 2008, por Horacio Martínez (Universidad de San Carlos, Guatemala). La investigación contempló un programa de excavación muy completo en todo el sitio, además de reconocimiento y sondeos en la región inmediata, en donde el sitio más lejano investigado hacia el norte ha sido El Raudal, y al sur, Sebol (figura 1). Los resultados arqueológicos fueron presentados de manera extensa en numerosas ocasiones (cf. Barrientos y Demarest, 2007; Demarest et al., 2007, 2008).

Cancuén fue una ciudad maya de gran importancia estratégica durante el Clásico Tardío (650-800 d.C.), y su historia refleja un desarrollo político lleno de eventos. Fundada en el 652 d.C. por un emisario de Calakmul, fue rápidamente sometida por la expansionista Dos Pilas (dominación evidenciada entre otros por la alianza matrimonial entre el poderoso Gobernante 3 y la Mujer de Cancuén, quien hizo construir su palacio y fue enterrada en el epicentro de Dos Pilas; Fahsen y Demarest, 2001: 35-36), hasta el colapso de dicha urbe en el 761 d.C. En esta fecha empieza una larga era de independencia, la del nuevo rey Taj Chan Ahk quien lleva a su comunidad hacia el apogeo (Fahsen y Jackson, 2002: 26; Fahsen et al., 2003: 29-30; Fahsen y Barrientos, 2006: 35-36; Barrientos y Demarest, 2007: 741).

La importancia de Cancuén reside en su ubicación estratégica en el río de la Pasión, en una zona fronteriza entre las llanuras de Tierras Bajas y las montañosas Tierras Altas de Alta Verapaz. Se considera el Altiplano como el área de extracción de bienes ausentes del Petén y codiciados por las poderosas ciudades del norte, tanto para usos cotidianos ( $\mathrm{vg}$. obsidiana, sal), como para usos rituales o elitistas ( $v g$. jade, pirita, entre los materiales visibles en arqueología). El rey Taj Chan Ahk parece haber tomado ventaja de la posición geográfica de Cancuén para hacer de ella un centro de intercambio entre las dos regiones. Es muy llamativa la presencia de talleres de manufactura de objetos de jade, materia prima importada desde algún lugar del valle del Motagua, modificado en Cancuén, y exportado hacia el norte bajo la forma de artefactos de lujo como orejeras, mosaicos, etc. (Kovacevich, 2006; Andrieu y Forné, 2010). La prosperidad de Cancuén en esta época se descubre gracias a la actividad constructiva que tuvo lugar en un corto tiempo: un palacio de impresionantes dimensiones, dos juegos de pelota en el centro, altares y estelas finamente esculpidos con estilo local inédito (Barrientos y Demarest, 2007; Demarest et al., 2007).

La edad de oro debía, sin embargo, terminar. Las huellas de violencia en Cancuén representan otro hecho notable para la arqueología en el área maya. 


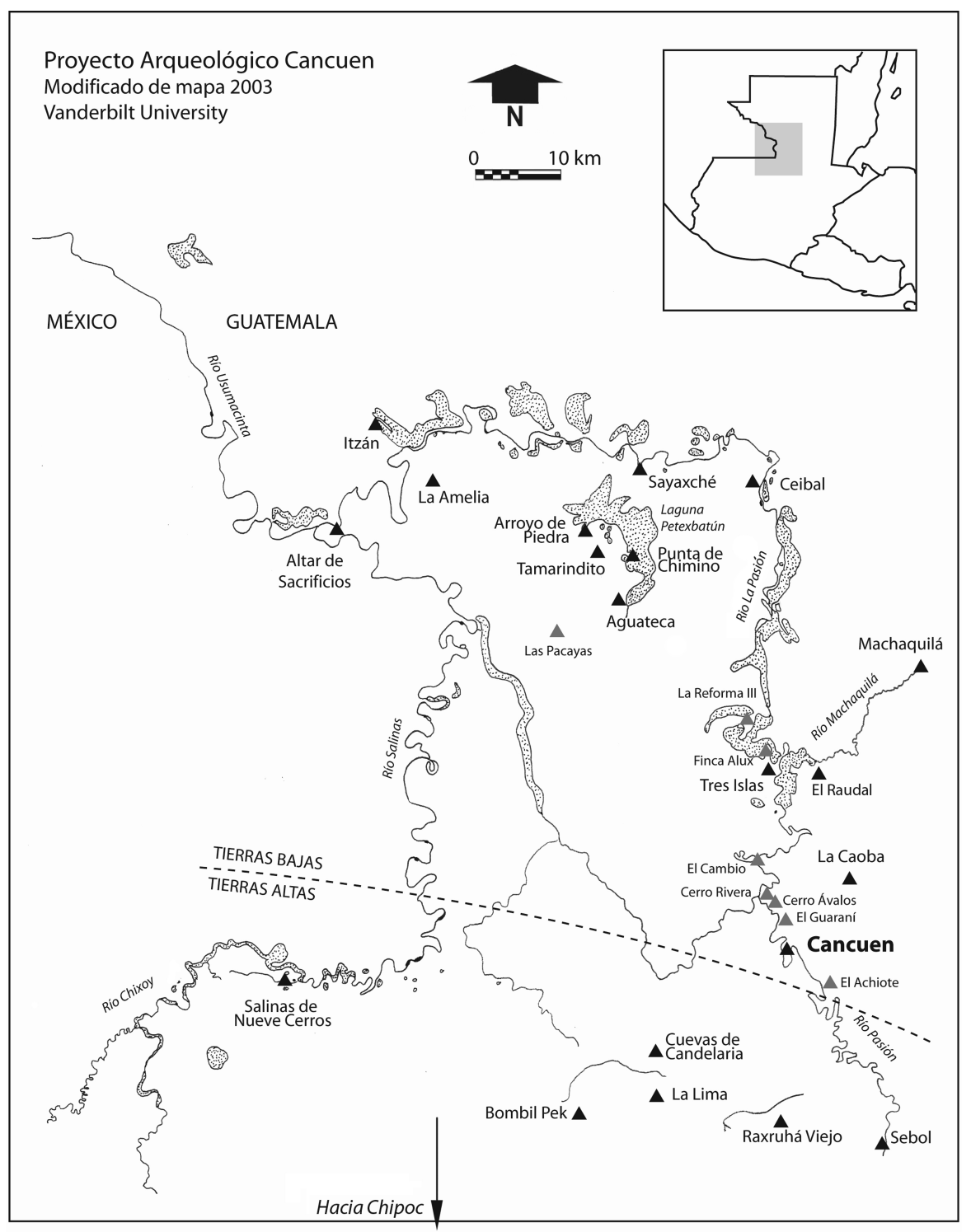

Figura 1. Mapa de la región de Cancuén donde se muestran los sitios mencionados en el texto. Modificado del mapa 2003, Proyecto Cancuén, Universidad de Vanderbilt 
Alrededor del 800 d.C., ocurrió la matanza de una parte de la población, que probablemente incluyó a varios miembros de la élite real del sitio, quienes fueron arrojados juntos con grandes cantidades de objetos personales en al menos dos reservas de agua del sitio. Estos contextos son muy escasos en el área maya prehispánica; por ello, son excepcionales. Las excavaciones revelaron un mínimo de 47 individuos en las dos aguadas, además de objetos cerámicos, de hueso y de madera (Alvarado, en prensa; Forné et al., 2009a). Estos eventos marcaron el fin de Cancuén, además de su abandono (Barrientos et al., 2006a: 329-330; Barrientos et al., 2006b; Alvarado y Mencos, 2008).

El sitio arqueológico se caracteriza por un patrón de asentamiento poco disperso (figura 2), organizado alrededor de un complejo palaciego de grandes dimensiones. Cuenta con una plaza cívico ritual y un juego de pelota monumental con altares esculpidos; al norte se ubican dos plazas abiertas, con otro juego de pelota y numerosas estructuras de élite, comunicadas con el sector Norte por medio de un largo sacbé. Este sector comprende talleres de jade, grupos residenciales y el tercer juego de pelota, de dimensiones más modestas. En fin, los sectores Oeste y Sur presentan grupos habitacionales más modestos. El río Pasión encierra todo el sitio, dejando una sola salida por tierra hacia el norte; se considera que varios puertos estuvieron en uso durante la época Clásica.

\section{Tipología cerámica}

La definición de los tipos se encuentra actualmente en curso, así como el análisis cerámico en general; sin embargo, los resultados más recientes permiten diseñar un panorama bastante completo de la colección cerámica de Cancuén. Dichos resultados se benefician en buena medida de los antecedentes de investigación representados por las clasificaciones anteriores dirigidas por Cassandra Bill (Bill, 2001; Bill y Callaghan, 2002; Bill, Callaghan y Castellanos, 2003). Los trabajos realizados por Brent Woodfill, en las cuevas de la región inmediata a Cancuén, contribuyeron también a nuestro entendimiento de la colección "multiregional" de Cancuén (Woodfill, 2007).

A manera de resumen, podemos decir que la cerámica de Cancuén se distribuye en cuatro partes, que estamos describiendo aquí como "conjuntos cerámicos" (Forné et al., 2008, 2009a, 2009b). Un conjunto cerámico consiste en la agrupación de unidades tipológicas características de una región específica, ya sea porque los recipientes provienen directamente de dicha región, o porque los estilos decorativo, morfológico o técnico son característicos de la producción cerámica de esta región.

Los cuatro conjuntos cerámicos de Cancuén fueron establecidos sobre todo en base a la tipología, ya que la mayoría de los análisis químicos de composición de pasta — que permitirán identificar la proveniencia de la materia prima— está 


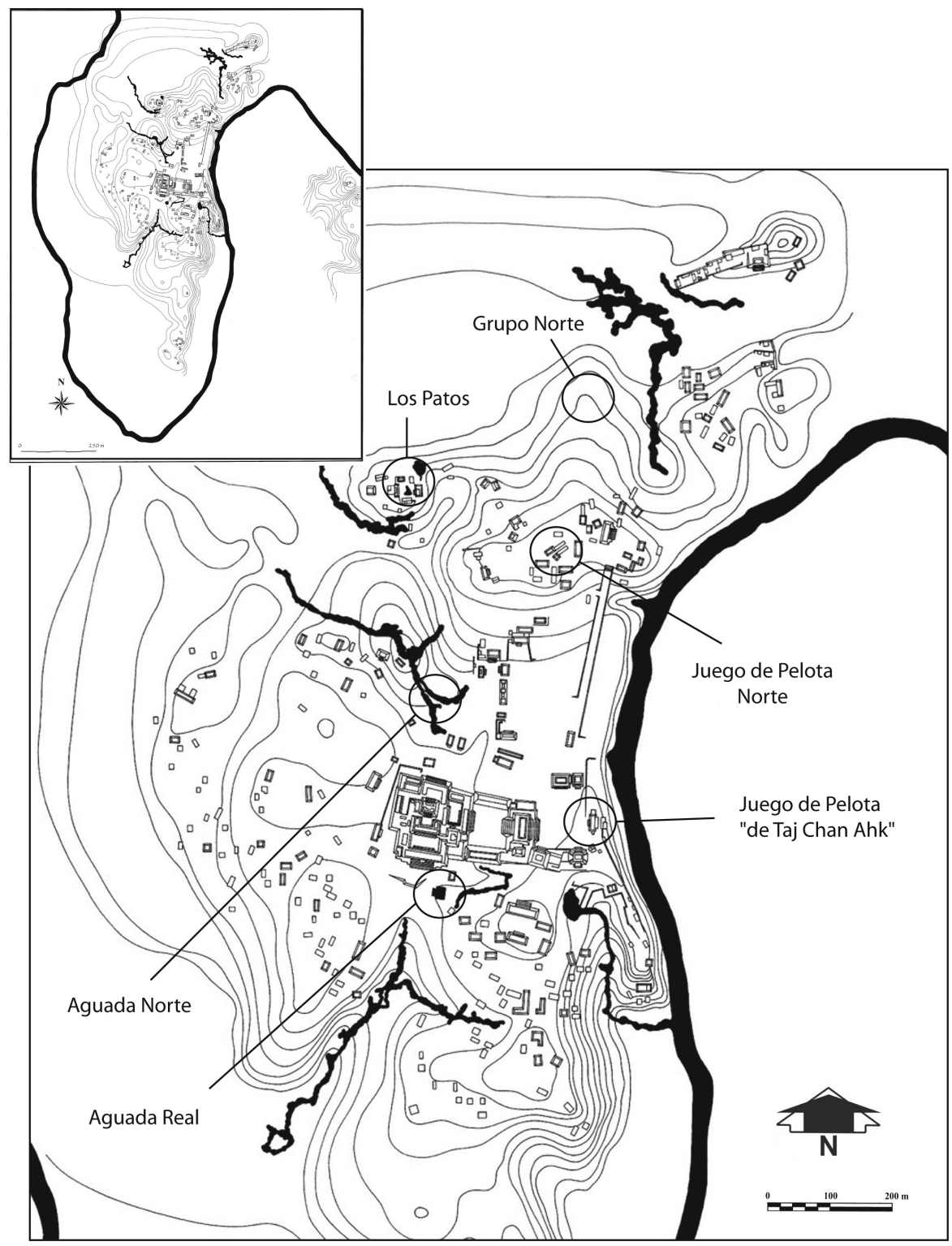

Figura 2. Mapa general de Cancuén con ubicación de los sectores citados. Dibujo de M. Wolf, 2005 
actualmente en curso (en colaboración con Ronald Bishop, Smithsonian Institution de Washington).

Es importante indicar que las proporciones presentadas en este artículo están calculadas sobre el total de tiestos (sin erosionar) de la clasificación realizada desde el 2007 bajo la responsabilidad de Mélanie Forné. Aunque las clasificaciones anteriores sean válidas y estén disponibles para el estudio, fueron realizadas con criterios de identificación a veces divergentes, y algunos tipos todavía eran desconocidos por lo cual no aparecían en los descuentos. Para presentar aquí resultados homogéneos, se decidió calcular las frecuencias con base en la clasificación reciente, que comprende un total de 13452 tiestos.

\section{Los cuatro conjuntos cerámicos de Cancuén}

El propósito de este artículo no es ofrecer una descripción exhaustiva de los cuatro conjuntos cerámicos, sino presentar una síntesis de ellos, presentando al lector una visión global de la colección y de sus características más representativas. Así, sólo se describieron los grupos cerámicos principales, ignorándose temporalmente los minoritarios.

La colección cerámica refleja las relaciones interregionales que pudo mantener la sociedad de Cancuén en el Clásico Tardío. El conjunto Petén, conformado por los tipos característicos de las Tierras Bajas del Petén durante el Clásico, es el más representado con el $59.80 \%$ de tiestos identificables (figura 3). ${ }^{1}$ El conjunto Cancuén es el segundo en frecuencias, con el $21.38 \%$ de la muestra; el conjunto Tierras Altas, con el $10.10 \%$ de la muestra; y el conjunto Costa del Golfo está poco representado, exclusivamente por vasijas de servicio, ${ }^{2}$ con el $0.99 \%$ de la muestra.

\section{Conjunto Petén}

En el conjunto Petén los tres grupos mayoritarios son: Cambio, Tinaja y SaxchePalmar. A continuación se hace una breve descripción de estos grupos (figura 3).

El grupo Cambio está representado en su gran mayoría por el tipo Cambio Sin Engobe, con una superficie alisada sin decorado, tratamiento muy común en toda las Tierras Bajas Mayas. Este grupo presenta poca variación morfológica: la gran mayoría de él está constituida por fragmentos de cántaros, entre los cuales más de la mitad tienen cuello corto, borde fuertemente evertido sin quiebre y

\footnotetext{
${ }^{1}$ Calculado sobre el total de tiestos clasificados desde el 2007, sin tomar en cuenta los erosionados.

${ }^{2}$ La vajilla cotidiana, conformada por grandes recipientes como los cántaros, genera grandes cantidades de tiestos, lo cual siempre tiende a aumentar las proporciones de materiales domésticos. En contraste, los cuencos y platos, de tamaño pequeño, crean una menor cantidad de desecho.
} 


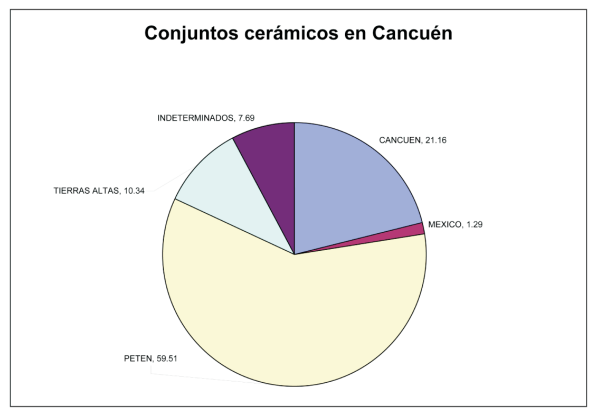

a) Frecuencia de los conjuntos cerámicos en Cancuén.
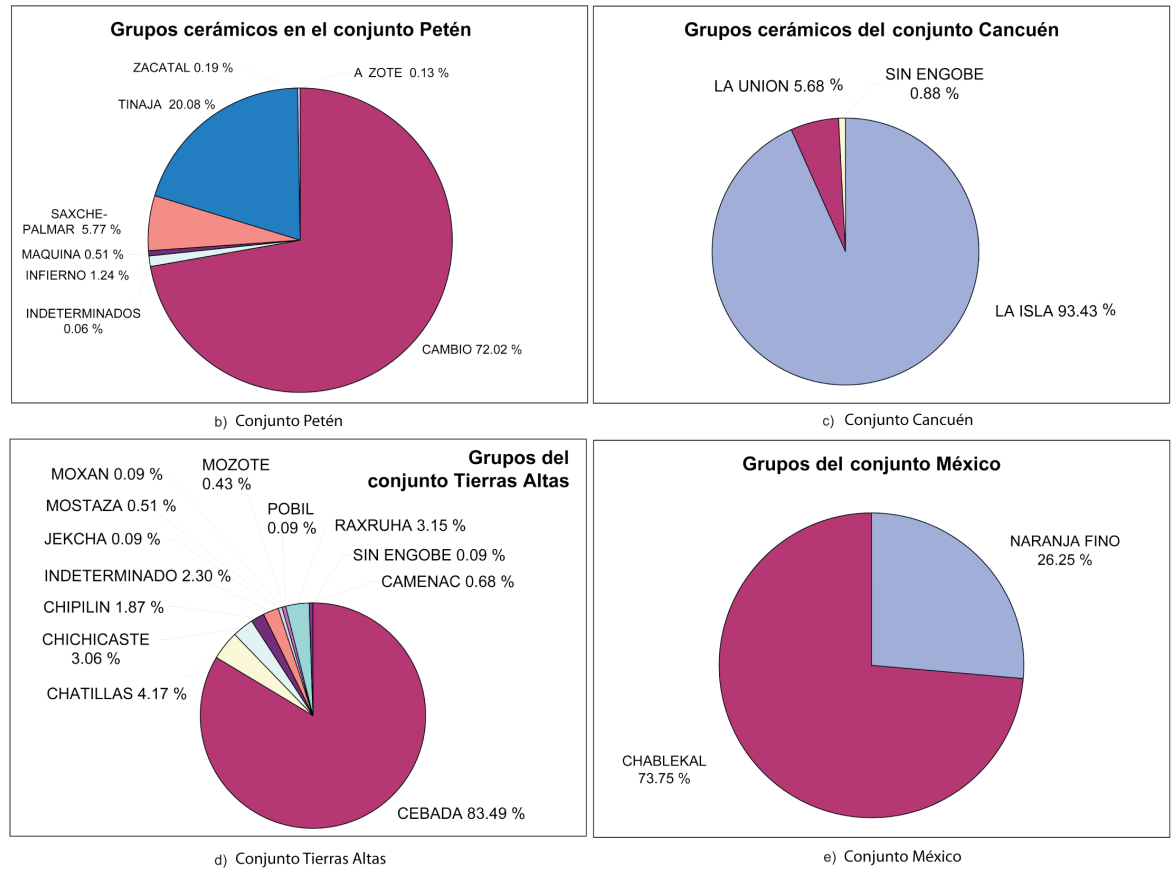

FiguRA 3. a) Frecuencias de los conjuntos cerámicos en Cancuén (colección clasificada desde el 2007: 24342 tiestos, sin contar los erosionados); b) conjunto Petén; c) conjunto Cancuén; d) conjunto Tierras Altas; e) conjunto Costa del Golfo

labio sencillo acanalado (figura 4). La pasta muestra abundantes inclusiones carbonatadas de tamaño mediano.

Es notable la casi ausencia de cántaros estriados, muy poco representados en la colección; mientras, el tipo Encanto Estriado es de lejos el mayoritario en las colecciones cerámicas sin engobe del Petén. Esto había sido observado anteriormente (Bill, 2001: 175-176; Bill y Callaghan, 2002: 476) y es un argumento para considerar la microregión de Cancuén como un área cerámica especial, que 

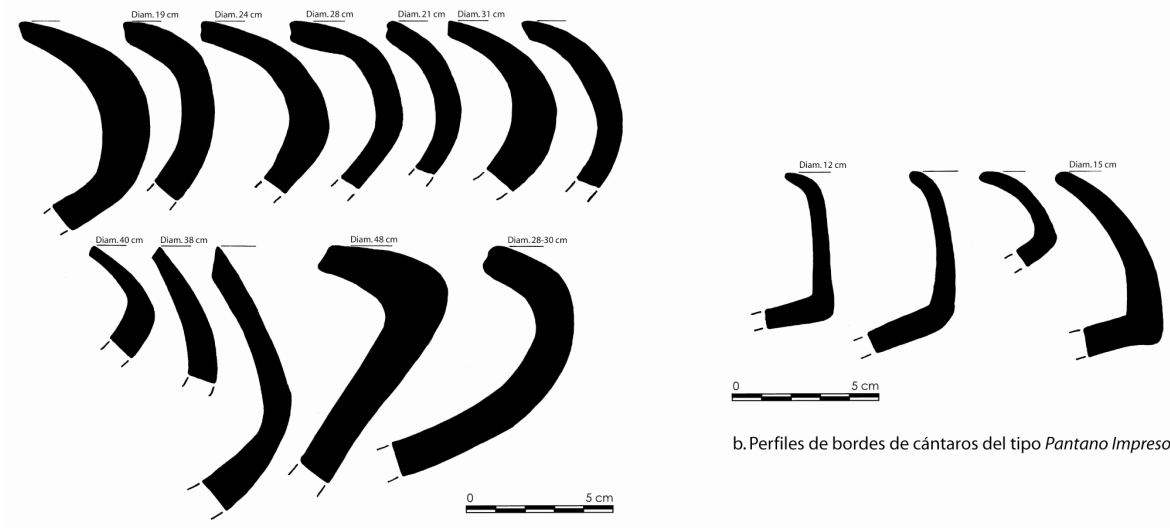

a. Perfiles de bordes de cántaros del grupo Cambio

b. Perfiles de bordes de cántaros del tipo Pantano Impreso

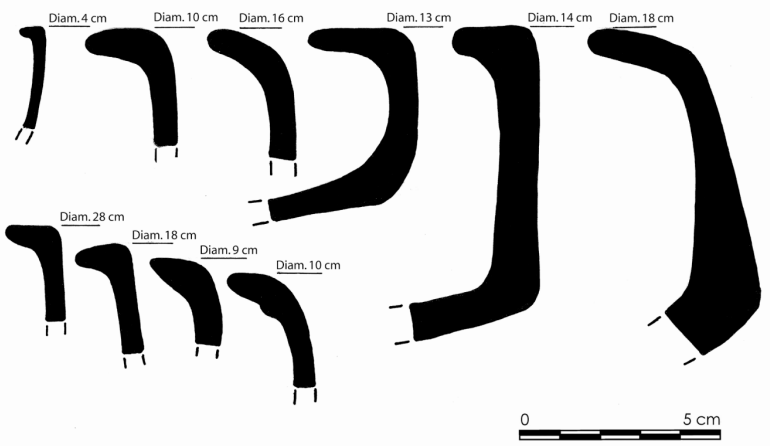

c.Perfiles de bordes de los cántaros más comunes en el grupo Saxche-Palmar

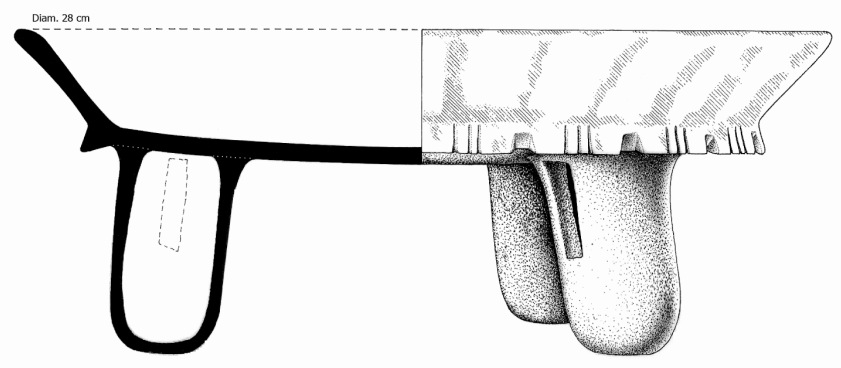

d. Plato del grupo Saxche-Palmar (dibujo L. Luin, 2008)

Figura 4. Cerámica del conjunto Petén: a) perfiles de borde de cántaros más comunes del grupo Cambio; b) perfiles de cántaros del tipo Pantano Impreso; c) perfiles de cántaros de tipo SaxchePalmar Polícromo Sobre Naranja; d) plato Saxche-Palmar Polícromo Sobre Naranja 
aunque comparte muchos tipos con las Tierras Bajas, presenta características propias.

El grupo Tinaja es el segundo mayoritario del conjunto Petén. La gran mayoría de los tiestos pertenecen a diferentes variedades del tipo Pantano Impreso, muy popular en el Petén y en el Petexbatún durante el Clásico Tardío. Sin embargo, al contrario de lo que ocurre en esta última región, la casi ausencia de Subin Rojo y las frecuencias muy bajas de Chaquiste Impreso y Zopilote Ahumado apartan a Cancuén de las esferas características del suroeste del Petén. Lo mismo que para el grupo Cambio, las variaciones en formas y diseños decorativos son mínimas (a comparación con las colecciones de un sitio como, por ejemplo, Ceibal; ver la descripción de formas en Sabloff, 1975: 158-159). Además, el tipo Tinaja Rojo, que en la mayoría de las colecciones del Petén presenta toda una variedad de formas para la vajilla de servicio (platos, cuencos y vasos), está casi exclusivamente representado por cántaros similares a Pantano Impreso (figura 4). En Cancuén, la mayoría de los tiestos del grupo Tinaja presenta una pasta rosada carbonatada característica, con desgrasante de caliza molida muy regular, pequeño y muy abundante.

La poca variación en pasta, formas y tipos de este grupo podría indicar, por un lado, un alto grado de especialización en la manufactura de estos recipientes; por otro lado, podría ser la manifestación de un abastecimiento en vasijas de una o pocas fuentes de producción. Además, tiende a alejar la colección de Cancuén de los modelos de las esferas cerámicas del Petén y de las Tierras Bajas en general.

Como en la gran mayoría de los sitios mayas del Clásico Tardío, el grupo Saxche-Palmar está presente con el tipo Saxche-Palmar Policromo Sobre Naranja, con pocas ocurrencias de Desquite Rojo Sobre Negro y Yuhactal Negro Sobre Rojo, y ausencia de Chantuori Negro Sobre Naranja (tipos populares en el Petén del Clásico Tardío).

Lo mismo que ocurre en los grupos Cambio y Tinaja, las variaciones en formas y modos decorativos son muy escasas: resalta la casi ausencia de vasos cilíndricos, así como la poca cantidad de cuencos hemisféricos. Las formas más frecuentes son, por un lado, los platos trípodes, con paredes rectodivergentes y borde directo o evertido y labio redondeado o afinado; por otro lado, son notables los pequeños cántaros, con un perfil inhabitual de cuello recto y vertical, con borde horizontalmente evertido muy plano y labio ligeramente afinado (figura 4). Este perfil es muy característico y fácilmente reconocible, con pocas variaciones morfológicas, lo cual podría apuntar hacia cierta especialización en su producción. Los pocos motivos decorativos que se alcanzan a identificar, a pesar de la erosión, son decorados geométricos sencillos; están ausentes las imágenes figurativas propias a los materiales policromos de Tierras Bajas o vasos códices. Los vasos cilíndricos con representaciones figurativas (como pudimos constatar en la ceramoteca del IDAEH en el 2007) tampoco están presentes en Cancuén (Foias, 1996).

La pasta de los recipientes del grupo Saxche-Palmar es muy homogénea, lo cual indica la uniformidad de manufactura, posiblemente debida a cierta estan- 
darización o al abastecimiento en una o pocas fuentes de producción. Generalmente es de color beige "durazno", con desgrasante carbonatado muy fino poco visible; en la mitad de los casos la pasta es muy dura, resultado de una buena cocción.

Una vez más, dada la poca variación de formas y decoración, consideramos que a pesar de la presencia formal del grupo Saxche-Palmar en Cancuén, la colección no se asemeja plenamente a la esfera cerámica Tepeu del Clásico Tardío.

En fin, se notó la presencia todavía no cuantificable de recipientes con engobe negro lustroso del grupo Infierno. La tradición de vasijas negras monocromas con o sin decoración se registra tanto en Tierras Altas como en Tierras Bajas, en algunos casos con formas y decorado muy similares. En Cancuén, desde los inicios del análisis cerámico, fue notoria la presencia abundante de vasijas negras, en general cuencos de tamaño pequeño. En algunos casos, la pasta, forma y decorado indica que son del grupo Infierno; en otros, es evidente que son de un estilo diferente, y en muchos casos todavía no se puede establecer la relación con algún área cultural (Bill y Callaghan, 2002: 477-479). Un análisis profundo está previsto para determinar las proporciones de material de los conjuntos Petén, Cancuén o Tierras Altas. Por el momento, el material está clasificado como Negro Pulido.

\section{Conjunto Cancuén}

Dentro del conjunto Cancuén (2834 tiestos), el grupo mayoritario es La Isla (figura 3). Este lleva la marca regional de Cancuén, tanto en decoración como en formas y pasta. Muy abundante en el sitio, no había sido identificado en el área maya (Bill, 2001: 164-169). Se destaca por sus formas inéditas y por una superficie naranja monocroma, lo cual se supone ya no está en uso en el Clásico Tardío de Tierras Bajas. La superficie está bien alisada, lustrosa, de color naranja encendido.

La pasta tiende a ser suave, anaranjada y con tendencia semiporosa, con desgrasante de carbonatos en mediana cantidad; se observa también una pasta dura y compacta, sobre todo en los cuencos grandes El Zapotal Impreso y La Isla Naranja, resultado de una cocción bien controlada. Varios tipos se establecieron en el pasado (Bill, 2001: 164-169), y se terminaron de definir recientemente (Forné et al., 2008: 215-217). El tipo mayoritario es El Zapotal Impreso, conformado por cuencos de gran tamaño, con engobe interno, y externo hasta debajo de una llamativa banda circunferencial de impresión de dedos (figura 5). El decorado es muy uniforme en todas las vasijas, y las formas son variaciones de un mismo modelo, con un perfil inédito en el Petén. Estos cuencos serían la versión local del cuenco grande con decoración impresa, muy popular en todas las Tierras Bajas Mayas (tipos Chaquiste Impreso y Chinjá Impreso), pero con otro color y otras formas (Forné, 2010).

El tipo La Isla Naranja corresponde sobre todo a la versión no decorada de El Zapotal Impreso. La vajilla de servicio está conformada por otros dos tipos: 

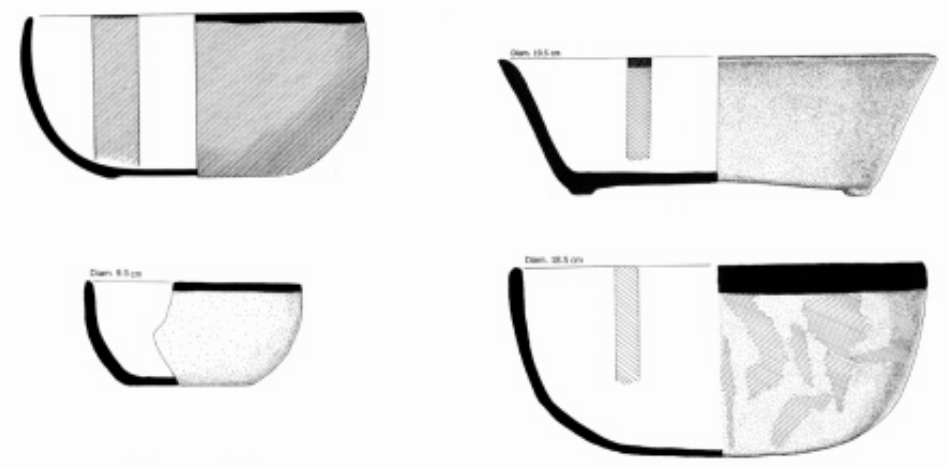

a. Cuencos tipos Cocales Bicromo

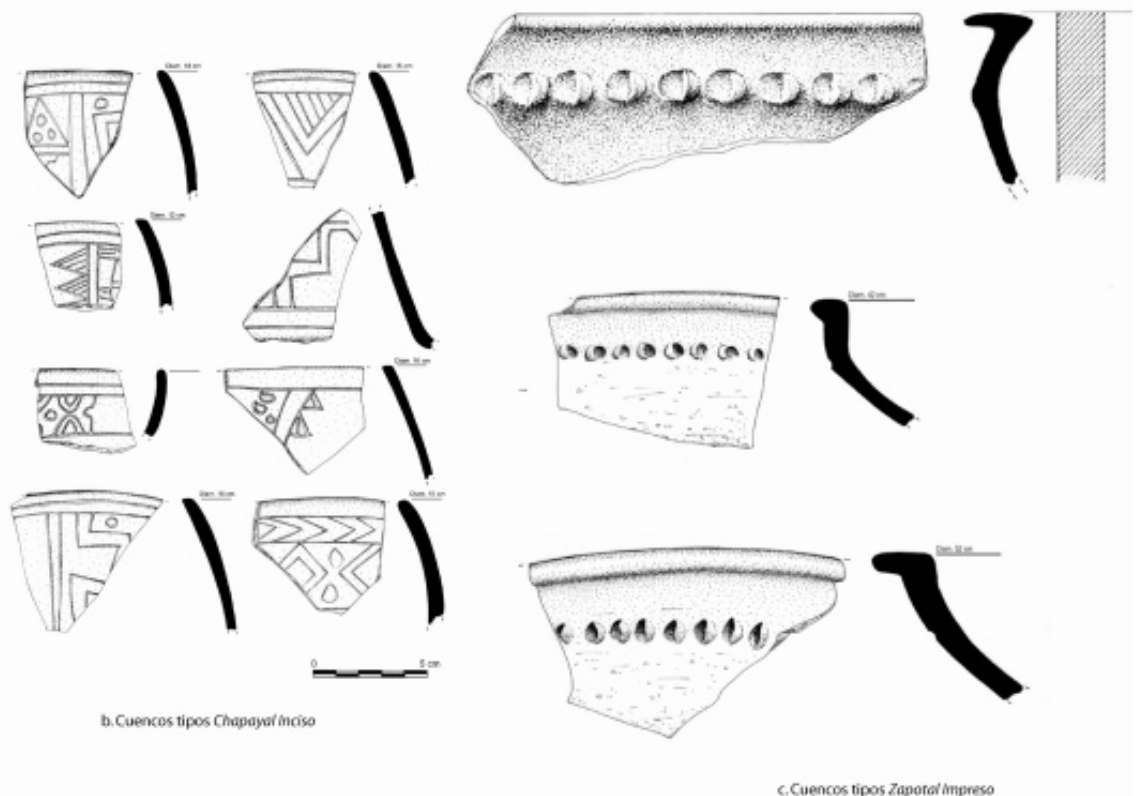

Figura 5. Cerámica del “Conjunto Cancuén”. a. Cuencos del tipo Cocales Bícromo; b. Fragmentos del tipo Chapayal Inciso; c. Perfiles del tipo El Zapotal Impreso

(dibujos: L. Luin, M. Forné, D. Belches, R. Macario)

Cocales Bícromo y Chapayal Inciso. El primero (anteriormente llamado Cuenco naranja con borde negro; Bill y Callaghan, 2002: 485), pertenece al grupo La Isla (Forné et al., 2008). Son cuencos pequeños (de entre 10 y $25 \mathrm{~cm}$ de diámetro), con engobe naranja y borde negro (figura 5) y presentan dos formas: cuenco 
hemisférico, o con paredes curvodivergentes, siempre con borde directo y labio redondeado. El tipo Chapayal Inciso (anteriormente Naranja Inciso; ver Bill y Callaghan, 2002: 485-486), corresponde a cuencos de paredes curvodivergentes o rectodivergentes, con diámetro promedio de $20 \mathrm{~cm}$, cuya superficie exterior está decorada con motivos incisos geométricos, o raras veces figurativos (figura 5). Este estilo es muy similar al de los cuencos incisos de Chipoc, un sitio pequeño ubicado debajo de la actual ciudad de Cobán (departamento de Alta Verapaz) en el cual se hallaron grandes cantidades de este material (como pudimos constatar en la ceramoteca del Instituto de Antropología e Historia de Guatemala en el 2006). Los análisis químicos ayudarán, esperemos, a determinar con mayor grado de precisión la proveniencia de los cuencos Chapayal Inciso. Sin embargo, el decorado de los cuencos de Cancuén no llega a la delicadeza del trazo inciso de los recipientes de Chipoc, por lo cual nos inclinamos a pensar que fueron producidos en un área local, imitando los ejemplares de esta última población.

En Cancuén, el grupo La Isla funciona como un equivalente al Tinaja, el cual es el grupo monocromo mayoritario en todos los sitios mayas de Tierras Bajas. Sus recipientes cumplen, a priori, estas dos funciones: 1 ) almacenamiento (los cuencos grandes El Zapotal Impreso reemplazan a los Chaquiste Impreso) con excepción de los cántaros, más abundantes en el grupo Tinaja, tipo Pantano Impreso; 2) servicio y consumo (los cuencos y platos, ausentes del grupo Tinaja de Cancuén, han sido reemplazados por cuencos y platos Cocales Bícromo y Chapayal Inciso).

Este grupo es muy abundante en Cancuén y casi ausente de todos los demás sitios (con excepción de lugares vecinos de Cancuén: El Guaraní, El Achiote, La Caoba; Forné et al., 2009a), por lo cual se plantea la hipótesis de que la producción del grupo La Isla fue exclusivamente local. Por lo mismo, esto refleja la existencia de un sistema de producción y distribución microrregional eficiente aunque muy poco extendido. En esta colección resalta la alta calidad de manufactura de los recipientes y aunque no ha sido realizado un análisis de estandarización para esta investigación, esto apuntaría hacia un sistema de producción especializado, mantenido por alfareros con muy buenas habilidades técnicas.

\section{Conjunto Tierras Altas}

El conjunto Tierras Altas está representado por varios tipos minoritarios, y por el abundante grupo Cebada. A pesar de sus bajas frecuencias generales, los grupos Raxruhá y Chichicaste son hasta la fecha los más característicos de la colección Tierras Altas de Cancuén, por lo cual se incluye aquí su descripción (figura 3).

El grupo Cebada está representado por un tipo único: Cebada Poroso, el cual sería el equivalente Tierras Altas de Cambio Sin Engobe. En este punto del análisis, dicho grupo está casi exclusivamente conformado por cántaros de gran tamaño muy parecidos a los de Cambio, con borde evertido y labio acanalado, y con cuello corto y curvo, o bien largo y recto (figura 4). La peculiaridad y prin- 
cipal atributo de identificación de este grupo es su pasta no carbonatada, muy porosa y sin desgrasante visible. Los hoyos de la porosidad se dejan observar en superficie, y son muy evidentes en la fractura de los tiestos. Se piensa que esta pasta contenía desgrasante vegetal, el cual desaparecía en el momento de la cocción del recipiente; esto provocaba una porosidad que, además de generar un peso muy ligero, funcionaba como un aislador térmico capaz de guardar el calor o la frescura del contenido del recipiente (Rice, 1987: 351). Este grupo fue establecido en Alta Verapaz (Arnauld, 1986: 329-330), se retomó para el estudio de las cuevas al sur de Cancuén (Woodfill, 2007: 425-428) y presenta fuertes similitudes con el sin engobe Osoquin, descrito en Salinas de los Nueve Cerros (Dillon, 1979: 51-52).

Los demás grupos de Tierras Altas corresponden a vasijas de servicio (cuencos y algunos vasos cilíndricos), entre los cuales los más característicos de la colección son los grupos Raxruhá y Chichicaste (figura 6). El primero fue establecido por las clasificaciones dirigidas por Cassandra Bill y se refiere a un material monocromo lustroso de color crema (Bill, 2001: 183-186). Recordemos que los materiales monocromos crema son muy escasos durante el Clásico, si no fuera por el tipo Harina Crema (Clásico Tardío), establecido en el Atlas Arqueológico de Guatemala (Laporte, 2007: 837) y muy escaso en las colecciones cerámicas en general. En Cancuén, el grupo Raxruhá es de superficie ligeramente lustrosa, o con tendencia a erosionarse más que sus equivalentes Tinaja Rojo y La Isla Naranja. La pasta carbonatada es rosada o beige, bastante fina, con poco desgrasante. El tipo más característico sería Nitro Inciso, con técnica de incisión postengobe que genera un diseño de color rosado con fondo crema, ya que la incisión deja ver el color natural de la pasta. Las investigaciones anteriores han descrito este tipo como Ojo de Agua Inciso, de la clase Crema sobre Mikado Café en Uaxactún y en Altar de Sacrificios (Smith, 1955: 34; Smith y Gifford, 1966: 160, 172; Adams, 1971: 44), o como Crema sobre Mikado Café Inciso en Chipoc (Smith, 1952: fig. $15)$.

La abundancia de este material en Chipoc, la cercanía geográfica de este sitio con respecto a Cancuén, así como la semejanza de los tiestos de ambas colecciones, nos hace plantear la hipótesis de que cierta proporción de estos recipientes fue directamente importada del primer sitio hacia Cancuén. Esta hipótesis está reforzada por el análisis de composición química de la vasija CANV $14,{ }^{3}$ que confirma su proveniencia directa desde Chipoc (Sears y Sejías, 2002: 108-109), lo cual nos confirma la existencia de relaciones de intercambio entre ambos sitios, identificables en una proporción todavía no cuantificable de cerámica.

El tipo Chichicaste Café, característico de Alta Verapaz (Arnauld, 1986: 337340; Woodfill, 2007: 464-473), es uno monocromo de color café diferente en formas y pasta al conocido Máquina Café del Petén. En aquel sólo se hallan

${ }^{3}$ La vasija CANV 14 es de tipo indeterminado Resistente Negro Sobre Crema, relacionado con el grupo Raxruhá por su engobe de color crema. 


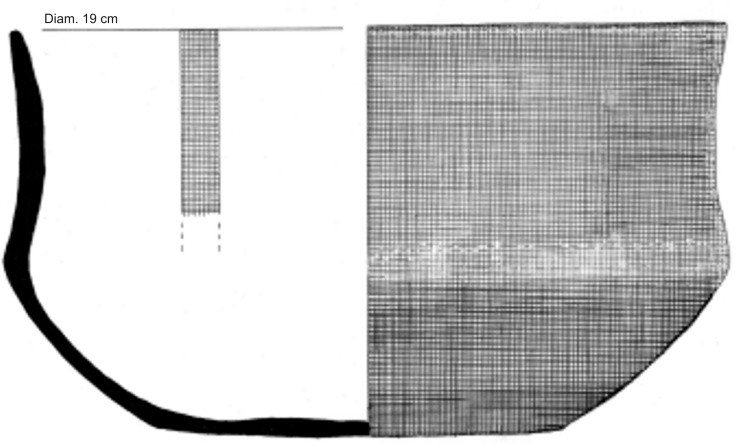

\section{Chichicaste Café}
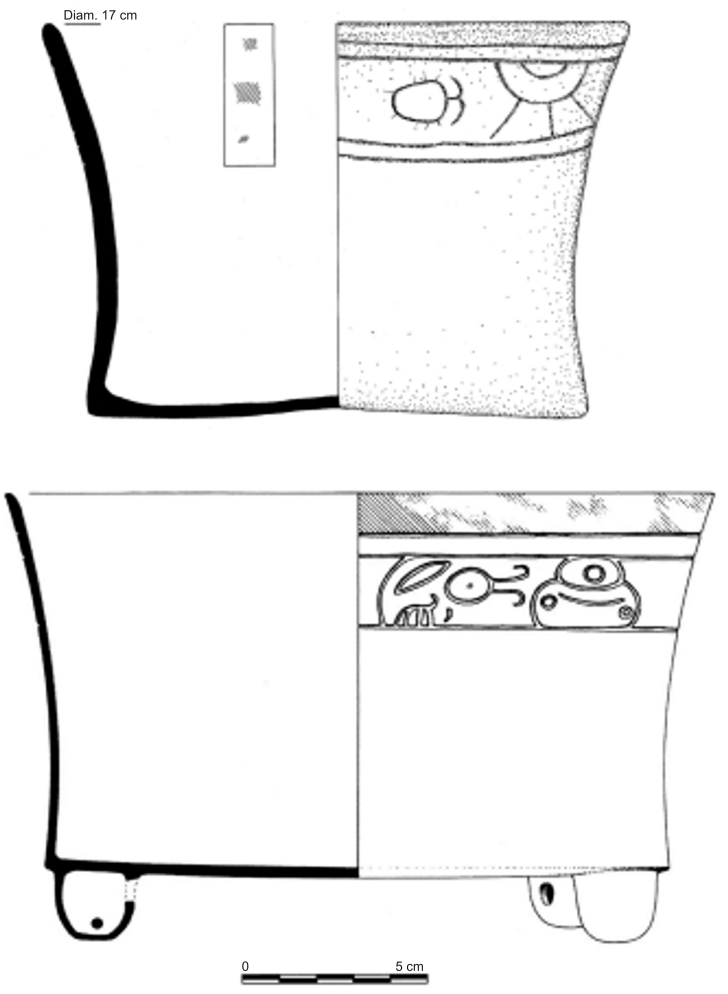

Nitro Inciso (grupo Raxruhá)

Figura 6. Cerámica del conjunto Tierras Altas.

Tipos Chichicaste Café y Nitro Inciso (grupo Raxruhá). Dibujos de R. Macario, A. Cajas y L. Luin 


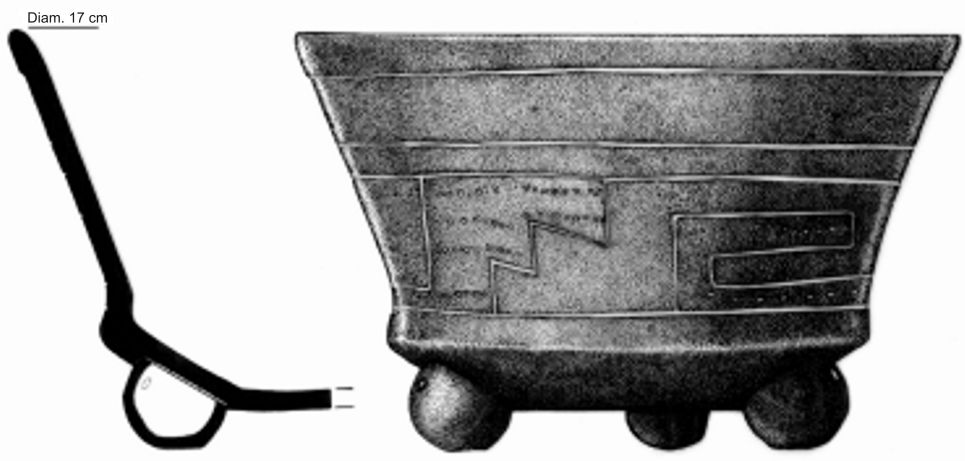

Telchac Compuesto: V. Negra
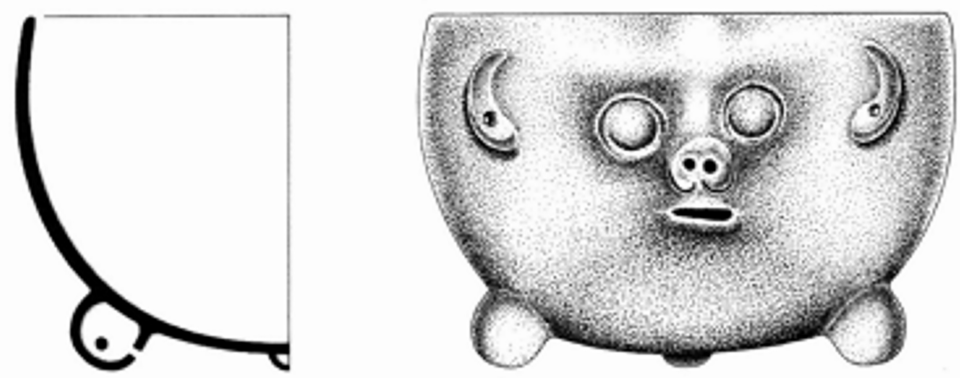

Gris Fino Modelado No Determinado
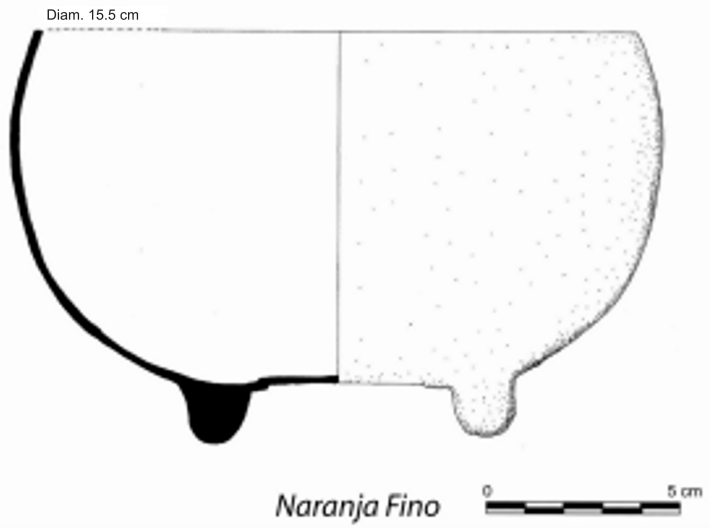

Figura 7. Cerámica del conjunto Costa del Golfo. Dibujos de A. Cajas, L. Luin y R. Macario 
cuencos pequeños con paredes curvas y pasta rojiza no carbonatada, mientras Máquina Café tiende a reproducir las formas típicas del grupo Tinaja: cántaros, cuencos grandes y pequeños, con pasta carbonatada rosada o beige. Es difícil hacer comparaciones interregionales en base a Chichicaste Café ya que la muestra es muy pequeña.

\section{Conjunto Costa del Golfo}

En fin, relacionados con el conjunto Costa del Golfo sólo están registrados los grupos Chablekal y Altar, respectivamente de las clases Gris y Naranja Fino (figura 3). El grupo Chablekal está representado en la colección por los tipos Chablekal Gris, Chicxulub Inciso, Telchac Compuesto y Alta Gracia Acanalado, algunos con más de una variedad (figura 7). Se trata únicamente de pequeños cuencos hemisféricos o de paredes delgadas, recto-divergentes y con la pasta característica de la clase Gris Fino. A pesar de que este grupo esta representado por al menos cuatro tipos, los recipientes presentan poca variación en formas, tamaños y pasta, reflejando una producción especializada de cuencos directamente importados de la región de Palenque (Ronald Bishop, comunicación personal, 2009; Forné et al., en prensa). Es importante recalcar la ausencia del grupo Tres Naciones, característico del Clásico Terminal en Tierras Bajas.

La clase Naranja Fino está poco representada (0.33\%), encontrándose en su mayoría formas sencillas sin decorado, especialmente cuencos hemisféricos con paredes delgadas, engobe rojo y, en varios casos, trípodes (figura 7). Es llamativa la total ausencia de las formas y decorados característicos del Naranja Fino del Clásico Terminal (vg. Pabellón Inciso-Modelado o Trapiche Inciso), bien conocidos en las colecciones de Altar de Sacrificios, Ceibal y el Petexbatún (Adams, 1971: 27, 30, 45, 46-47, 49-51; Sabloff, 1975: 189-209; Foias, 1996: 674-701).

Aunque es sabido que el Naranja Fino aparece en el Petén hasta el 830 d.C. (fecha establecida en base a los complejos de Altar de Sacrificios; ver Adams, 1971: 106, 135-137, 151; Sabloff, 1975: 9), existen en Cancuén fuertes evidencias para considerar que existe un Naranja Fino temprano, el cual aparece antes de los conocidos grupos del Clásico Terminal: Altar y Tres Naciones (Forné et al., 2010). Este argumento se basa en las siguientes evidencias: 1) ausencia del grupo Tres Naciones y, no obstante, presencia de Naranja Fino; 2) contemporaneidad comprobada estratigráficamente de Chablekal y Naranja Fino; 3) formas y decorado sencillos de los cuencos Naranja Fino; 4) ausencia de las formas y decorados característicos de las pastas finas del Clásico Terminal (platos trípodes con incisiones hondas, cilindros de barril, pedestal, decorado en plano-relieve, etc.).

Aunque es todavía imposible determinar una fecha absoluta para la aparición de este material, debemos admitir que se manifiesta en el Petén antes del 830 d.C., y después del 760 d.C. (fecha admitida para la aparición de Chablekal). Por su presencia discreta en Cancuén, podría haber aparecido después de Chablekal, 
por lo cual proponemos como fecha tentativa y simbólica el 800 d.C., en espera de que los análisis futuros nos permitan resolver este problema cronológico.

Los análisis de procedencia de la arcilla por medio de activación de neutrones, y en curso con el apoyo de R. L. Bishop y M. J. Blackman (Smithsonian Institution de Washington), ya aportaron datos esenciales para la comprensión del origen de los Gris y Naranja Fino de Cancuén. Basados en el análisis de 14 muestras de Naranja Fino y 113 muestras de Gris Fino, apareció de manera clara que la mayoría de los cuencos Gris Fino fueron importados desde una región situada al norte de Palenque, mientras los Naranja Fino, ahora identificado como del tipo Campamento Naranja Fino, estaban directamente importados de la región de la Chontalpa (sur de Veracruz, México; R. L. Bishop, comunicación personal, 2009; Forné et al. 2010).

\section{Cronología de Cancuén: los complejos cerámicos}

Con base en la clasificación cerámica, la tipología, la evaluación de los contextos de excavación y un estudio estadístico de los datos, fue establecida la secuencia cronocerámica de Cancuén. Anteriormente se habían descrito los periodos de este sitio, sustentados provisionalmente en datos cerámicos e históricos (Callaghan y Bill, 2004: 367-370; 398-409). Los periodos llevaban nombres preliminares que hacían referencia a la esfera Tepeu del Petén Central (Tepeu 2a temprano, Tepeu 2a, Tepeu 2a/2b y Tepeu 2b). Pero según sus mismos autores, los cambios cronológicos de la cerámica todavía estaban por ser confirmados, y la cronología todavía estaba pendiente de ser finalizada (Callaghan, comunicación personal 2006). Por eso fue esencial completar el estudio y establecer los complejos cerámicos de Cancuén.

La secuencia cronológica se presenta en la figura 8, donde se aprecia la evolución de los tipos cerámicos en el tiempo. Mientras cada línea representa una capa arqueológica (o un conjunto de capas estratigráficamente relacionadas), desde la más temprana (abajo) hacia la más tardía (arriba), las columnas corresponden a los tipos cerámicos temporalmente diagnosticados, identificados en la colección, y presentados según su orden de aparición: desde los más tempranos, a la izquierda, hasta los más recientes, a la derecha. Cada rectángulo representa la frecuencia de los tipos dentro de una capa, permitiendo una apreciación visual clara de la evolución de la cerámica en el tiempo.

Las unidades tipológicas utilizadas para elaborar esta gráfica son en realidad una mezcla de tipos, variedades o a veces grupos. En efecto, se ha observado con anterioridad que puede resultar más relevante agrupar ciertas categorías diagnósticas cuando son contemporáneas para llegar a darles mayor peso estadístico y visibilidad en las gráficas (Forné, 2006). De lo contrario, los tipos cuantitativamente mayoritarios pueden ocultar ciertas variaciones diagnósticas más discretas, de algunas categorías de poco peso cuantitativo; en consecuencia, 


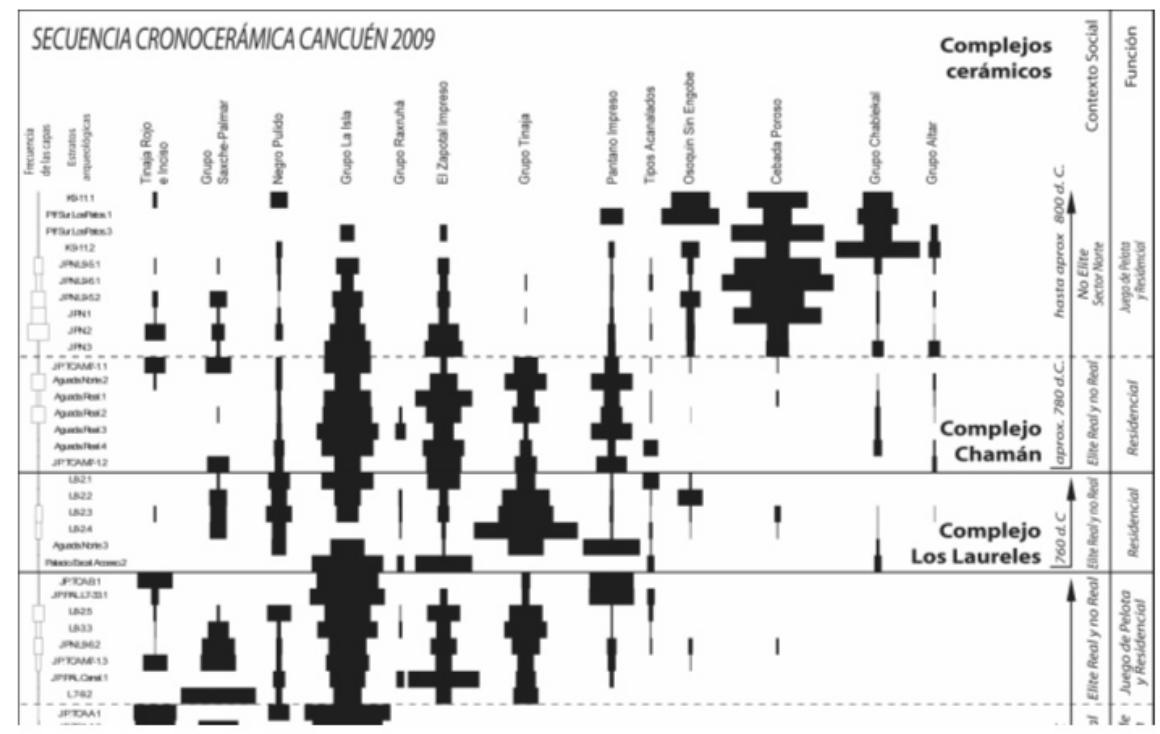

Figura 8. Secuencia cronocerámica de Cancuén

el analista puede llegar a perderse cambios cronológicos significativos aunque discretos.

La definición de los complejos cerámicos está basada en la aparición, desaparición o cambios significativos en la frecuencia de los tipos cerámicos. La secuencia revela tres complejos cerámicos, que se describen a continuación. Los nombres de los complejos fueron tomados de las fincas cercanas al sitio.

\section{Complejo Concordia}

El complejo Concordia corresponde al inicio del Clásico Tardío y, por ello, a la primera época de la historia de Cancuén. Principia hacia el 650 d.C., fecha propuesta con base en la fundación de la ciudad en el 656 d.C. La fecha final, sugerida como 760 d.C., es bastante tardía, y a pesar de que la historia de la ciudad conoció fuertes cambios a lo largo de cien años, por el momento ninguna evidencia cerámica nos permite diferenciar fases temporales dentro de este largo complejo. Aunque los análisis anteriores habían propuesto la idea de unos cambios morfológicos entre diferentes cuencos de tipo El Zapotal Impreso (Bill y Callaghan, 2002: 468-469; Callaghan y Bill, 2004: 368-369), el estudio actual no permitió confirmar esta hipótesis.

No obstante, no debemos ocultar la existencia de dos periodos históricos dentro de este complejo cerámico: el primero corresponde a la fundación del sitio y su sumisión a Calakmul; el segundo, marcado por la hegemonía de Dos Pilas sobre Cancuén, confirmada por la alianza matrimonial entre la "mujer de 
Cancuén” y el Gobernante 3, quién reinó entre el 727 y el 741 d.C. (Fahsen y Demarest, 2001: 35). Dicho dominio acaba con el colapso de Dos Pilas hacia el 760 d.C., fecha que tanto históricamente como en la cerámica sufre cambios relevantes.

En cerámica, el complejo Concordia destaca por el conjunto de tipos característicos de las Tierras Bajas del Sur: grupos Cambio, Tinaja y Saxche-Palmar, además de la presencia de los grupos La Isla (con el abundante El Zapotal Impreso) y Raxruhá.

\section{Complejo Los Laureles}

El complejo Los Laureles (anteriormente Tepeu 2a/b) corresponde al final del Clásico Tardío, una época comprendida entre el ascenso del rey Taj Chan Ahk (consecutivo al final de la hegemonía de Dos Pilas en el 760 d.C.) y antes de la aparición del Naranja Fino temprano. Este periodo está marcado por el apogeo de Cancuén bajo la dirección de su nuevo rey, y por una nueva y fuerte dinámica constructiva en el epicentro de la ciudad (Callaghan y Bill, 2004: 401-404).

En cerámica, el diagnóstico más significativo es la presencia del grupo Chablekal, cuya aparición está fechada en las Tierras Bajas en el 760 d.C. (Foias, 1996: 589). Los tipos presentes en concordia siguen siendo abundantes.

\section{Complejo Chaman}

El complejo Chaman es el último de la cronología y empieza en una fecha difícil de definir, ya que está marcado sobre todo por la aparición del Naranja Fino temprano descrito anteriormente, y que no puede ser fechado de manera absoluta. Sin embargo, en la información estratigráfica es posible advertir un lapso (de duración no determinable) entre la aparición del Gris Fino y la del Naranja Fino. Como la última fecha escrita con referencia a Cancuén es el 800 d.C., podría proponerse el inicio del complejo Chamán alrededor del 780 d.C., considerando un lapso simbólico de veinte años. Estamos en espera de que datos futuros permitan refinar esta propuesta, pero es todavía imposible proponer un rango de fechas totalmente satisfactorio.

Este periodo corresponde a los últimos años de Taj Chan Ahk y al reino de su hijo Kaan Ma’x, el cual aparentemente apenas gobernó cuatro años, hasta el final dramático que llevó al abandono completo y definitivo de la ciudad.

A nivel cerámico, además de la aparición de Naranja Fino, se observa el aumento de la presencia del grupo Cebada (y su equivalente Osoquín, no descrito en este artículo; Forné et al., 2009a; 2009b). Este dato permite dividir Chaman en dos subcomplejos, diferenciados únicamente con base en un factor social: el primero conformado por capas arqueológicas provenientes de contextos asociados con la élite (Aguada Real, Aguada Norte, Juego de Pelota “de Taj Chan Ahk”); el segundo definido por contextos modestos como el Juego de Pelota Norte, el Grupo Norte y 
el Grupo Los Patos (figura 1). Aunque es necesario profundizar el análisis y aportar datos de más contextos arqueológicos, podemos plantear la hipótesis, a partir de estos resultados, según la cual los habitantes de diferentes sectores y categorías sociales de Cancuén no utilizaban los mismos tipos de recipientes, diferencia visible no tanto a nivel funcional sino respecto a los estilos cerámicos.

Algunos resultados preliminares sugerían la posibilidad de que ciertos conjuntos cerámicos estuvieran asociados con algunos sectores de Cancuén. Es llamativa la fuerte asociación casi exclusiva de materiales del conjunto Petén con los contextos de élite, o la del sector del Juego de Pelota Norte con frecuencias más altas de materiales del conjunto Tierras Altas (Forné et al., 2008). Aunque todavía esto constituya una simple hipótesis, este tema de investigación se está desarrollando y esperamos poder brindar resultados acerca de los vínculos culturales de los habitantes de Cancuén, visibles a partir del material cerámico.

\section{Episodio Posclásico}

Aunque es imposible definir un complejo cerámico para el Posclásico, porque no se aprecia ninguna ocupación humana tangible en Cancuén durante esta época, debemos señalar la existencia de unas pocas evidencias posteriores al abandono. La clasificación cerámica reveló la presencia de tiestos posclásicos en varios sectores (tipos Chilo Sin Engobe, Pozo Sin Engobe, Paxcaman Rojo y algunos plomizos). Este material fue encontrado prioritariamente en la zona norte del sitio, en los grupos Los Patos (tres tiestos), Aguada Norte (un tiesto), Grupo K8 (57 tiestos); la mayoría de las piezas fue hallada en los grupos residenciales del noreste (cuadrante M9: 492 tiestos; cuadrante M10: un tiesto), para un total de 554 tiestos y una vasija parcial (hallada arriba de la estructura residencial de élite L8-2) en la colección.

Las evidencias posclásicas en Tierras Bajas del Sur se encuentran en general en contextos posteriores al abandono, muy cerca de la superficie y en capas no selladas, lo cual dificulta excesivamente su fechamiento absoluto. Basándonos en datos comparativos, especialmente en los datos del complejo Tamarindito en el Petexbatún (Foias, 1996: 712-720), podemos proponer una fecha entre el 950 y 1200 d.C.

\section{Conclusiones}

Finalmente, al cabo de diez años de investigación del Proyecto Cancuén se puede presentar una cronología constituida por tres complejos, definidos por su contenido cerámico, con fechas absolutas y nombres propios. La división en fechas que ha sido propuesta en este artículo no es satisfactoria y debe entenderse como tentativa, pues faltarían datos de fechas absolutas para comprobarla. Aunque las definiciones detalladas de estos complejos puedan sufrir cambios en el 


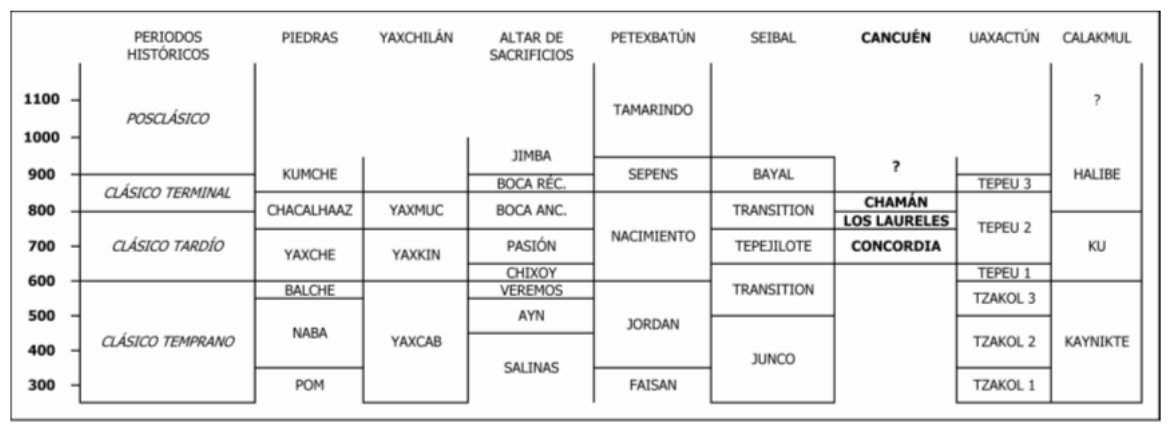

(según Martin y Grube 2000: 8-9; Muñoz, Acuña y Pérez 2002: 1; López Varela 1989: 45; Adams 1971: 137,150; Foias 1996; Sabloff 1975: 9; Dominguez Carrasco 1994: 321)

FiguRa 9. Cuadro cronológico de los principales sitios de Tierras Bajas, incluyendo a Cancuén

futuro (el análisis cerámico prosigue actualmente en el laboratorio del Proyecto Cancuén), dichos periodos pueden ahora considerarse como una base de referencia para los estudios comparativos que puedan llevarse al cabo en regiones cercanas o lejanas.

La historia de Cancuén es muy corta, lo que contrasta con las cronologías de los sitios de las Tierras Bajas, donde muchos de los asentamientos investigados presentan secuencias largas de ocupación (figura 9). Por lo mismo, los complejos cerámicos de Cancuén son pocos, y no están definidos por variaciones tipológicas muy fuertes. Más bien, son escasos los cambios a lo largo del tiempo. Es importante resaltar que los estudios de cronología cerámica muy pocas veces permiten hacer divisiones temporales muy finas (raramente se pueden definir periodos de menos de 50 años). Esto nos indicaría que las modas cerámicas probablemente no evolucionaban de manera muy rápida, y a pesar de ciertos cambios bruscos y repentinos (vg. la introducción del Gris Fino como marcador del inicio de una dinámica de intercambio con una región lejana), los hábitos de producción de los alfareros no parecen haber evolucionado mucho en el marco de 200 años, ni en Cancuén ni en otros sitios mayas de las Tierras Bajas.

En cambio, la sucesión de eventos políticos es mucho más rápida, y en el caso de Cancuén, la epigrafía permite restituir parte de la historia política, la cual se puede dividir en al menos cuatro periodos (tomados de Fahsen y Barrientos, 2006: 35-44):

656 a 691 d.C. Cancuén está bajo el dominio directo de Calakmul ${ }^{4}$ 691 a 761 d.C. $\quad$ Cancuén está bajo el dominio de Dos Pilas ${ }^{5}$

\footnotetext{
${ }^{4}$ Aunque existe una referencia epigráfica al año 653 d.C., se ubica generalmente la fundación de Cancuén en el 656 d.C., con el ascenso del primer gobernante Ch'aba Ahaw (Fahsen y Demarest, 2001: 33; Fahsen y Barrientos, 2006: 35; Demarest et al., 2008).

${ }^{5}$ En esta época está registrada la alianza matrimonial entre el Gobernante 3 de Dos Pilas y la “mujer de Cancuén”, en algún momento entre el 727 y el 741 d.C. (Fahsen y Demarest, 2001: 35).
} 
761 a 780 d.C. Cancuén florece bajo el mando independiente de Taj Chan Ahk 780 a 800 d.C. Cancuén (Taj Chan Ahk) controla a Machaquilá ${ }^{7}$

Queremos recalcar aquí las diferencias que separan la cronología histórica de la cerámica. La primera está definida por eventos puntuales que marcan los cambios importantes a nivel político ( $\mathrm{gg}$. alianzas, el ascenso o muerte de un gobernante). Estos eventos tienen repercusiones fuertes sobre la historia de la comunidad, y están definidos por fechas absolutas, identificadas por un récord epigráfico establecido por los mismos mayas. Esta cronología es muy importante para entender la sucesión de los eventos ocurridos, las relaciones políticas interregionales, y para investigar el desarrollo de la ciudad, desde su fundación hasta su abandono total.

En cambio, la secuencia cronocerámica indica la evolución de la producción, consumo e intercambio de los recipientes cerámicos en el sitio. Aquella no está directamente relacionada con los datos epigráficos: por eso, cualquier fechamiento establecido para la aparición o desaparición de un tipo o conjunto de tipos,

\section{CRONOLOGÍA DE CANCUÉN}

Elaborada en base a datos epigráficos y cerámicos

Forné, 2009

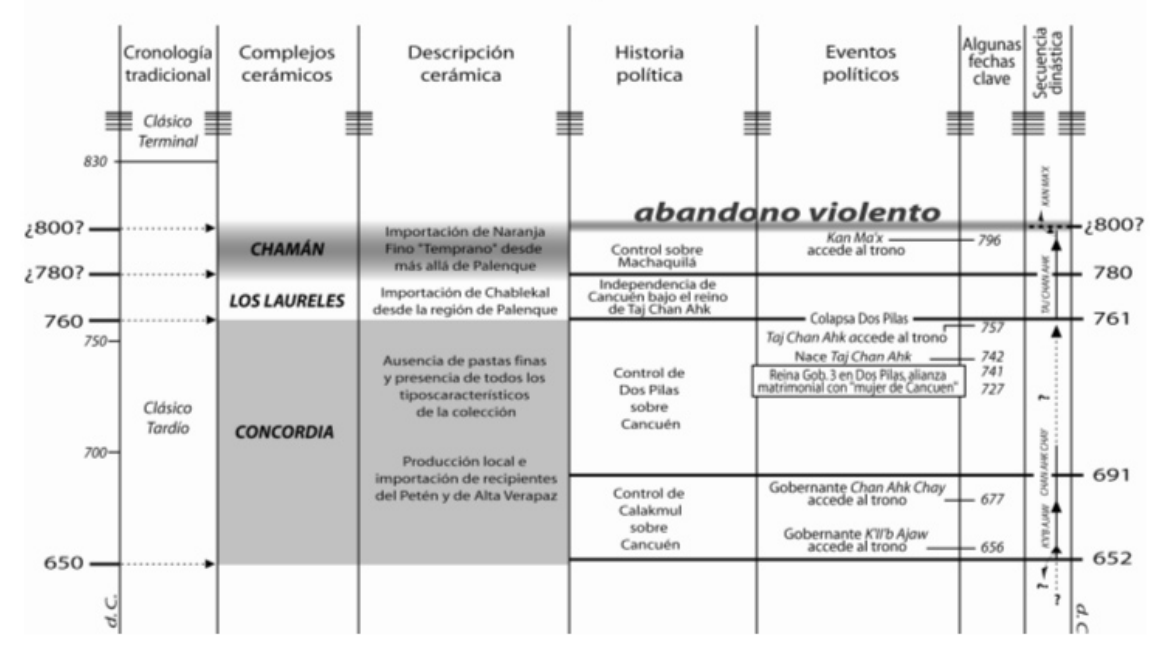

Figura 10. Cronología de Cancuén, basada en los datos epigráficos y cerámicos. Según el análisis cerámico (Forné et al., en prensa) y el estudio epigráfico (Fahsen y Demarest, 2001; Fahsen y Jackson, 2002; Fahsen, Demarest y Luin, 2003; Fahsen y Barrientos, 2006; Barrientos y Fahsen, 2006)

${ }^{6}$ Taj Chan Ahk, nacido en el 742 d.C., asciende al poder en el 757 d.C. (Fahsen y Barrientos, 2006: 35).

${ }^{7}$ Durante este periodo, Kan Ma'x, hijo de Taj Chan Ahk, asciende al poder alrededor de el 796 d.C., pero sólo reina durante cuatro años (Fahsen y Barrientos, 2006: 43). 
tiene que ser indirecto, definido por comparación intra e interregional. Esta cronología constituye una herramienta invaluable para fechar (aunque de manera poco precisa en comparación con la secuencia histórica) los vestigios excavados.

Las dos secuencias cronológicas (histórica y cerámica) no siempre serán compatibles, ya que los hábitos de producción de los alfareros y las dinámicas de intercambio no siempre tienen que modificarse en función de los cambios políticos, aunque siempre puede haber correlación entre ambas partes. Es importante tener en mente las limitantes de ambas cronologías y no confundir sus posibilidades e implicaciones para la interpretación. Para esto, el resultado cronológico final de este estudio reside en la figura 10, que presenta la correlación y comparación entre las dos cronologías de Cancuén.

El análisis cerámico en Cancuén no está finalizado aun y quedan grandes cantidades de material por estudiar, y varios tipos por establecer: por consiguiente, los resultados presentados en este artículo podrán sufrir cambios. Sin embargo, consideramos que de hoy en adelante las bases para la cronología y tipología están bastante firmes y suficientemente adelantadas para poder ser usadas como base de comparación para los estudios venideros que podrán llevarse a cabo en la región, tanto en las Tierras Bajas como en las Tierras Altas.

\section{BIBLIOGRAFÍA}

Adams, Robert E. W.

1971 The ceramics of Altar de Sacrificios. Cambridge [Estados Unidos]: Harvard University Press, Peabody Museum Press (Papers of the Peabody Museum of Archeology and Ethnology, vol. 63, núm. 1).

Alvarado, Silvia

En prensa "Las reservas de agua en Cancuén: análisis de su contexto y función”, ponencia presentada en el XXIII Simposio de Investigaciones Arqueológicas en Guatemala, julio del 2009, Guatemala.

Alvarado, Silvia y Elisa Mencos

2008 "CAN 48: excavaciones en la cisterna o reserva de agua norte", "Proyecto Arqueológico Cancuén, informe final 2007”. Horacio Martínez Paiz, Arthur A. Demarest, Mélanie Forné y Luis Luin (eds.), Vanderbilt/Universidad de San Carlos de Guatemala. Informe entregado a la Dirección General del Patrimonio Cultural y Natural, Guatemala, 79-113.

Andrieu, Chloé y Mélanie Forné

2010 "Producción y distribución del jade en el mundo maya: talleres, fuentes y rutas del intercambio en su contexto interregional: vista desde Cancuén”, XXIV Simposio de Investigaciones Arqueológicas en Guatemala, 2009. Bárbara Arroyo, Adriana Linares Palma y Lorena Paiz Aragon (eds.). Guatemala: Museo Nacional de Arqueología, 947-956. 
Arnauld, Charlotte

1986 Archéologie de l'habitat en Alta Verapaz (Guatemala), México: Centro de Estudios Mexicanos y Centroamericanos (Collection Etudes Mesoaméricaines, núm. 10).

Barrientos, Tomás, Arthur A. Demarest, Silvia Alvarado, Horacio Martínez, Marc Wolf y Luis Fernando Luin

2006a "Hidráulica, ecología, ideología y poder: nueva evidencia y teorías en el sur de Petén”, XIX Simposio de Investigaciones Arqueológicas en Guatemala, Juan Pedro Laporte, Bárbara Arroyo y Héctor Mejía (eds.). Guatemala: Asociación Tikal/Museo Nacional de Arqueología y Etnología, 319-332.

Barrientos, Tomás, Silvia Alvarado y Horacio Martínez

2006b "Investigaciones en el drenaje Sur de la Piscina Real de Cancuén”, "Proyecto Arqueológico Cancuén Informe Final 2004-2005”, Tomás Barrientos, Arthur Demarest, Luis Luin y Brent Woodfill (eds.). Informe entregado a la Dirección del Patrimonio Cultural y Natural, Guatemala, 453-482.

Barrientos, Tomás y Federico Fahsen

2006c "Nuevos monumentos e inscripciones de Cancuén", "Proyecto Arqueológico Cancuén Informe Final 2004-2005”, Tomás Barrientos, Arthur Demarest, Luis Luin y Brent Woodfill (eds.). Informe entregado a la Dirección del Patrimonio Cultural y Natural, Guatemala, 57-72.

Barrientos, Tomás y Arthur A. Demarest

2007 "Cancuén: puerta del mundo maya clásico", XX Simposio de Investigaciones Arqueológicas en Guatemala, Juan Pedro Laporte, Bárbara Arroyo y Héctor Mejía (eds.). Guatemala: Museo Nacional de Arqueología y Etnología, 737755.

Bill, Cassandra

2001 "Tipología y análisis preliminar de la cerámica de Cancuén”, "Proyecto Arqueológico Cancuén, Informe Final 2000”, Arthur A. Demarest y Tomás Barrientos (eds.). Informe entregado a la Dirección General del Patrimonio Cultural y Natural, Guatemala, 161-216.

Bill, Cassandra y Michael Callaghan

2002 "Frecuencias relativas de los tipos y modos cerámicos en Cancuén”, "Proyecto Arqueológico Cancuén, Informe Final 2001”, Tomás Barrientos y Arthur Demarest (eds.). Informe entregado a la Dirección General del Patrimonio Cultural y Natural, Guatemala, 251-264.

Bill, Cassandra, Michael Callaghan y Jeannette Castellanos

2003 "La cerámica de Cancuén y la región del Alto Pasión", "Proyecto Arqueológico Cancuén, Informe Final 2002”, Arthur A. Demarest, Tomás Barrientos, Brigitte Kovacevich, Michael Callaghan y Luis F. Luin (eds.). Vanderbilt University/Universidad del Valle de Guatemala. Informe entregado a la Dirección General del Patrimonio Cultural y Natural de Guatemala, 467-522. 
Callaghan, Michael y Cassandra Bill

2004 "Análisis cerámico por sector residencial”, “Proyecto Arqueológico Cancuén, Informe Final 2003”, Arthur A. Demarest, Tomás Barrientos, Luis F. Luin y Brent Woodfill (eds.). Vanderbilt University/Universidad del Valle de Guatemala. Informe entregado a la Dirección General del Patrimonio Cultural y Natural de Guatemala, 365-508.

Demarest, Arthur A., Tomas Barrientos, Mélanie Forné, Marc Wolf, Ron Bishop, Claudia Arriaza, Waleska Belches y Jose Luis Garrido

2007 "La nueva historia de la Puerta a las Tierras Bajas: descubrimientos recientes sobre la interacción, arqueología y epigrafía del sitio Cancuen”, XXI Simposio de Investigaciones Arqueológicas en Guatemala, 2006, Juan Pedro Laporte, Bárbara Arroyo y Héctor Mejía (eds.). Guatemala: Asociación Tikal/Museo Nacional de Arqueología y Etnología.

Demarest, Arthur A., Brent Woodfill, Marc Wolf, Tomás Barrientos, Ronald Bishop, Mirza Monterroso, Edy Barrios, Claudia Quintanilla y Mathilde Ivic

2008 "De la selva a la tierra: investigaciones a lo largo de las rutas ribereñas y terrestres del occidente", XXI Simposio de Investigaciones Arqueológicas en Guatemala, 2007, Juan Pedro Laporte, Bárbara Arroyo y Héctor Escobedo (eds.). Guatemala: Asociación Tikal/Museo Nacional de Arqueología y Etnología.

Dillon, Brian D.

1979 "The archaeological ceramics of Salinas de los Nueve Cerros, Alta Verapaz, Guatemala", tesis para obtener el grado de Philosophy Doctor. Berkeley: University of California.

Fahsen, Federico y Arthur A. Demarest

2001 "El papel del reino de Cancuén en la historia de las Tierras Bajas mayas: nuevos datos epigráficos", "Proyecto Arqueológico Cancuén, Informe Final №2, Temporada 2000”, Arthur A. Demarest y Tomás Barrientos (eds.). Informe entregado a la Dirección General del Patrimonio Cultural de Guatemala.

Fahsen, Federico y Sarah Jackson

2002 "El panel de Cancuén: nuevos datos e interpretaciones sobre la dinastía de Cancuén en el periodo Clásico", "Proyecto Arqueológico Cancuén, Informe Final 2001”, Tomás Barrientos, Arthur A. Demarest y Luis Luin (eds.). Informe entregado a la Dirección General del Patrimonio Cultural y Natural, Guatemala, 21-32.

Fahsen, Federico, Arthur A. Demarest y Luis Luin

2003 "Setenta años de historia en la Escalinata Jeroglífica de Cancuén", "Proyecto Arqueológico Cancuén, Informe Temporada 2002”, Arthur A. Demarest, Tomás Barrientos, Brigitte Kovacevich. Michael Callaghan y Luis Luin (eds.). Informe entregado a la Dirección General del Patrimonio Cultural y Natural, Guatemala, 27-42. 
Fahsen, Federico y Tomás Barrientos

2006 "Los monumentos de Taj Chan Ahk y Kan Ma’x", "Proyecto Arqueológico Cancuén Informe Final 2004-2005”, Tomás Barrientos, Arthur A. Demarest, Luis Luin y Brent Woodfill (eds.). Informe entregado a la Dirección del Patrimonio Cultural y Natural, Guatemala, 35-56.

Foias, Antonia

1996 "Changing Ceramic Production and Exchange Systems and the Classic Maya Collapse in the Petexbatun Region", tesis para obtener el grado de Philosophy Doctor. Nashville: Vanderbilt University, Department of Anthropology.

Forné, Mélanie

2006 La cronología cerámica de La Joyanca, Petén Noroccidente, Guatemala. Eric Taladoire (ed.). Oxford: ArcheoPress (British Archaeological Reports, International Series 1572/Paris Monographs in American Archaeology, 17).

2010 "Variante y variación en la cerámica maya regional: interpretación en tres sitios del oeste del Petén, Guatemala", Figuras mayas de la diversidad, Aurore Monod Becquelin, Alain Breton y Mario Humberto Ruz (eds). Mérida: Universidad Nacional Autónoma de México, Centro Peninsular en Humanidades y Ciencias Sociales, 335-365.

Forné, Mélanie, Silvia Alvarado, Paola Torres, Claudia Arriaza y Raquel Macario

2008 "Estudio de la cerámica de Cancuén: un nuevo comienzo", "Proyecto Arqueológico Cancuén, Informe Final 2007”. Horacio Martínez, Arthur A. Demarest, Mélanie Forné y Luis Luin (eds.). Vanderbilt University/Universidad de San Carlos de Guatemala. Informe entregado a la Dirección General del Patrimonio Cultural y Natural, Guatemala, 211-272.

Forné, Mélanie, Silvia Alvarado, Paola Torres y Diana Belches

2009a "Análisis cerámico de Cancuén y su región: perspectivas cronológica y cultural”, "Proyecto Arqueológico Cancuén, Informe final no 9, Temporada 2008", Arthur A. Demarest, Horacio Martínez, Mélanie Forné, Claudia Quintanilla y Luis Luin (eds.). Informe entregado al Instituto de Antropología e Historia, Guatemala.

Forné, Mélanie, Arthur A. Demarest, Horacio Martínez, Paola Torres, Silvia Alvarado y Claudia Arriaza

2009b "Intercambio y afiliación cultural en Cancuén: la complejidad cultural en las vísperas del colapso", "XXII Simposio de Investigaciones Arqueológicas en Guatemala, 2008”. Juan Pedro Laporte, Bárbara Arroyo y Héctor E. Mejía (eds.). Guatemala: Ministerio de Cultura y Deporte, Instituto de Antropología e Historia y Asociación Tikal, 1017- 1036.

Forné, Mélanie, Ronald L. Bishop, Arthur A. Demarest, M. James Blackman, Erin L. Sears

2010 "Gris Fino, Naranja Fino: presencia temprana y fuentes de producción, el caso de Cancuén", XXIV Simposio de Investigaciones Arqueológicas en Guatemala, 2009. Bárbara Arroyo, Adriana Linares Palma y Lorena Paiz Aragon (eds.). Guatemala: Museo Nacional de Arqueología, 1163-1182. 
Kovacevich, Brigitte

2006 Reconstructing classic maya economic systems: production and exchange at Cancuen, Guatemala, tesis para obtener el grado de Philosophy Doctor. Nashville: Vanderbilt University.

Laporte, Juan Pedro

2007 La secuencia cerámica del sureste de Petén: tipos, cifras, localidades, y la historia del asentamiento. Guatemala: Ministerio de Cultura y Deportes, Dirección del Patrimonio Cultural y Natural (Monografía 3. Atlas Arqueológico de Guatemala).

Rice, Prudente M.

1987 Pottery Analysis. A Sourcebook. Chicago/Londres: University of Chicago Press.

Sabloff, Jeremy A.

1975 Excavations at Seibal, Department of Petén, Guatemala. Number 2: Ceramics. Cambridge [Estados Unidos]: Harvard University. (Memoirs of the Peabody Museum of Archeology and Ethnology, 13).

Sears, Erin y Ronald L. Bishop

2002 "Variabilidad en la composición de las pastas en el área de Cancuen, Guatemala: figurillas y pastas finas", XV Simposio de Investigaciones Arqueológicas en Guatemala, 2001, Juan Pedro Laporte, Héctor Escobedo y Bárbara Arroyo (eds.). Guatemala: Museo Nacional de Arqueología y Etnología, 495-504.

Sears, Erin y Alejandro Sejías

2002 "Investigaciones en la zona Oeste del Epicentro de Cancuén”, Proyecto Arqueológico Cancuén, Informe Final 2001, Tomás Barrientos y Arthur A. Demarest (eds.). Informe entregado a la Dirección General del Patrimonio Cultural y Natural, Guatemala, 103-128.

Smith, Robert E.

1952 Pottery from Chipoc. Alta Verapaz, Guatemala. Washington, D. C.: Carnegie Institution of Washington (Publication 596, Contribution 56).

1955 Ceramic Sequence at Uaxactun, Guatemala, vol. I y II. Nueva Orleans: Tulane University (Middle American Research Institute Publication, 20).

Smith, Robert E. y James C. Gifford

1966 Maya Ceramic Varieties, Types, and Wares at Uaxactun: Supplement to "Ceramic Sequence at Uaxactun, Guatemala”. Nueva Orleans: Tulane University, Middle American Research Institute (Middle American Research Records, III (1-5); Middle American Research Institute Publication, 28).

Woodfill, Brent

2007 "Shrines of the Pasion-Verapaz region, Guatemala: ritual and exchange along an ancient trade route", tesis para obtener el grado de Philosophy Doctor. Nashville: Vanderbilt University. 
